DOI 10.37882/2223-2982.2021.05.02

\title{
ФУНКЦИОНИРОВАНИЕ БЕЗЭКВИВАЛЕНТНЫХ ТЕРМИНОВ В АНГЛИЙСКОМ ЯЗЫКЕ И АНАЛИЗ ИХ ПЕРЕВОДА НА РУССКИЙ ЯЗЫК (НА МАТЕРИАЛЕ АМЕРИКАНСКИХ ЭКОНОМИЧЕСКИХ ЖУРНАЛОВ)
}

\section{FUNCTIONING OF NON-EQUIVALENT \\ TERMS IN ENGLISH AND ANALYZING \\ THEIR TRANSLATION INTO RUSSIAN (ON THE MATERIAL OF AMERICAN ECONOMIC JOURNALS)}

\section{E. Ambartsumyan}

Summary: The relevance of the topic of research in the article is due to the expansion of economic cooperation between Russian and American companies and the growing volume of communication and interaction in this professional sphere. The article discusses the peculiarities of the functioning and translation of non-equivalent terms in English, in specialized economic texts on the material of American magazines. Analysis of the translation of non-equivalent terms discussed in the article confirms that they reflect the professionally oriented knowledge of native speakers and linguocultural factors. The purpose of the study is to study the process of functioning of non-equivalent terms in English and analyzing their translation into Russian (on the material of American economic journals). The article was prepared on the basis of generalizing theoretical and practical provisions of domestic studies in this direction. The article discusses in detail the key methods and receptions of transferring the Russian language of non-equivalent terms in English, which are found in the materials of American economic journals. With the refinement of optimal techniques for the transfer of non-equivalent economic terms in the American version of the English language, the corresponding patterns are indicated. It was revealed and established that the main cause of non-equivalence is the differences in the realities of practical professional reality leading to the absence in the language of translation of certain concepts in a foreign language. The results of the study in the article make it possible to talk about the importance of continuously studying the process of functioning of non-equivalent specialized terms in the American version of the English language and analyzing their translation into Russian on the material of modern specialized sources in the field of professional activities.

Keywords: non-equivalent terms, linguocultural functions, English, translation analysis, Russian, US economic realities.
Амбарцумян Екатерина Меружановна

Преподаватель, ФГОБУ ВО «Финансовый университет при

Правительстве Российской Федерачии» katrin01_89@mail.ru

Аннотация: Актуальность темы исследования в статье обусловлена расширением экономического сотрудничества между российскими и американскими компаниями и растущим объемом общения и взаимодействия в этой профессиональной сфере. В статье рассмотрены особенности функционирования и перевода безэквивалентных терминов в английском языке, в специализированных экономических текстах на материале американских журналов. Анализ перевода безэквивалентных терминов, рассмотренных в статье, подтверждает, что они отражают профессионально ориентированные знания носителей языка и лингвокультурологические факторы. Цель исследования состоит в изучении процесса функционирования безэквивалентных терминов в английском языке и анализе их перевода на русский язык (на материале американских экономических журналов). (татья подготовлена на основе обобщения теоретических и практических положений отечественных исследований в этом направлении. В статье подробно рассматриваются ключевые способы и приемы перевода на русский язык безэквивалентных терминов в английском языке, которые встречаются в материалах американских экономических журналов. При уточнении оптимальных приемов перевода безэквивалентных экономических терминов в американском варианте английского языка обозначены соответствующие закономерности. Выявлено и установлено, что основная причина безэквивалентности - различия в реалиях практической профессиональной действительности, ведущие к отсутствию в языке перевода тех или иных понятий на иностранном языке. Результаты исследования в статье позволяют говорить 0 важности постоянного изучения процесса функционирования безэквивалентных специализированных терминов в американском варианте английского языка и анализа их перевода на русский язык на материале современных специализированных источников в сфере профессиональной деятельности.

Ключевые слова: безэквивалентные термины, лингвокультурологические функциии, английский язык, анализ перевода, русский язык, американские экономические реалии. роблемы перевода специализированной безэквивалентной лексики с английского языка на русский, а также системы терминологии в английском языке рассматривалась неоднократно отечественными учеными (Л.И. Борисовой, Б.Н. Головиным, О.В. До- вбыш, Л.А. Капанадзе, Л.К. Латышевым, В.М. Овчаренко, Н.М. Разинкиной, А.А. Реформаторским и др.).

Например, в работе Л.И. Борисовой представлены особенности перевода общеупотребительной и обще- 
научной лексики с английского языка на русский [1]. Б.Н. Головин рассматривает роль терминологии в научном и учебном общении, на уровне термина и слова [2]. О.В. Довбыш исследует английскую финансовую терминологию и проблемы ее перевода на русский язык на материале годовых финансовых отчетов зарубежных компаний. По мнению О.В. Довбыш, «терминология может рассматриваться как система, организующая особый жанр текста, который играет важнейшую роль в деловой коммуникации.» [3, с.8]. Л.А. Капанадзе уделяет особое внимание понятиям «термин» и «терминология», процессу развития лексики современного русского языка [4].

Особый интерес для нашего исследования в статье представляет курс перевода Л.К. Латышева, где подробно рассматриваются эквивалентность перевода и способы ее достижения [5]. Термины, аналитическое наименование и номинативное определение, а также современные проблемы терминологии в науке и технике широко представлены в работе В.М. Овчаренко [6]. Н.М. Разинкиной проанализировано развитие языка английской научной литературы [7]. Исследование А.А. Реформаторского уточняет понятия «термин» и «терминология», а также вопросы терминологии в деталях[8].

Анализ вышеуказанных источников позволяет сделать вывод о том, что проблема нашего исследования рассматривалась неоднократно, однако были учтены по большей части лингвистические новинки специализированной литературы британского варианта английского языка и в меньшей степени специализированная экономическая терминология американского варианта английского языка.

Материалом для исследования процесса функционирования безэквивалентных терминов в английском языке и анализа их перевода на русский язык послужили тексты американских экономических журналов $[9,10]$.

Сопоставление терминосистем американского варианта английского языка и русского языка позволяет выявить, какие именно языковые единицы могут быть использованы для обеспечения адекватности перевода безэквиваленных экономических терминов, применяемых в США, исходя из ресурсов специальной лексики в сфере экономической профессиональной деятельности в РФ.

Заметим, что необходимым условием межъязыковой специализированной коммуникации является эквивалентность экономических терминов, конституирующих информацию в профессионально ориентированном тексте на английском языке и языке перевода.

Рассмотрим способы перевода безэквивалентных экономических терминов американского варианта английского языка. Подчеркнем, что безэквивалентность характерна для небольшого числа однословных терминов, и лишь некоторые из них участвуют в формировании производных составных терминов. Если значение безэквивалентного ключевого термина передает русский термин близкой семантики, то и в переводе производного термина соответствующий терминоэлемент рекомендуется переводить тем же способом. В подавляющем большинстве случаев для передачи значения составного термина может использоваться калькирование.

На примере мини-словаря, составленного на материале американских экономических журналов, возможно более четко увидеть безэквивалентные термины английского языка, отражающие американские экономические реалии и не имеющие эквивалентов в русском языке по своему содержанию. Безэквивалентные экономические термины представлены в нашей выборке единичными случаями. При их переводе применяются следующие приемы: подбор русского термина с близким значением; транскрипция, транслитерация; описательный перевод.

Рассмотрим применение этих способов перевода на русский язык (на материале американских экономических журналов) на практике:

- account group - сотрудники рекламного агентства, работающие на одного клиента, имеющего счет в фирме;

- actual allotment - бюджетные ассигнования, утвержденные Конгрессом США;

- appropriation bill - финансовый законопроект, предусматривающий выделение средств на осуществление программ, одобренных «санкционирующим законопроектом» Конгресса США;

- apportionment - пропорциональное распределение (предполагаемой) суммы налогов между отдельными штатами США;

- biennium - срок, на который выделяются финансовые средства в законодательных собраниях штатов США;

- break - внезапное падение цен;

- bullionist - сторонник металлического денежного обращения;

- NASDAQ OMX Group, Inc. - американская компания, владелец биржи Nasdaq и ещё восемь европейских бирж, входящих в состав концерна OMX Group, ныне - Nasdaq Nordic;

- Dow Jones DJIA - Индекс Доу - Джонса- средний показатель курсов акций группы крупнейших компаний США, название получил от публикующей его фирмы Доу-Джонса и представляет среднеарифметическую величину ежедневных котировок на момент закрытия биржи;

- NASDAQ - Индекс NASDAQ - американский индекс 
высокотехнологичных компаний, рассчитывается на основании котировок акций всех компаний, торгуемых во внебиржевой системе NASDAQ;

- NASDAQ Composite (IXIC) - Индекс Nasdaq Composite - это взвешенный по показателю капитализации индекс 3000 обыкновенных акций, торгуемых на бирже Nasdaq;

- The Federal Reserve - Федеральная Резервная Система США (ФРС) - объединение 12 федеральных резервных банков, выполняющих в совокупности функции Центрального банка США, а также коммерческие банки, являющиеся членами ФРС.

Особо отметим, что при переводе вышеуказанных безэквивалентных составных экономических терминов в американском варианте английского языка следует обращать внимание на их структуру: какой именно терминоэлемент означает не свойственный системе русского языка интегральный или дифференциальный признак, формирующий понятие, не имеющее аналогов в категориальной системе русского языка. Например, прием транслитерации при переводе может использоваться ограниченно: с одной стороны, он требует наличия у термина определенного фонетического строя и окончания, способствующего последующему образованию падежных форм существительного, а с другой, необходимо соответствующее включение заимствования в систему понятий соответствующей области, в т.ч. профессиональной. При переводе подавляющего большинства безэквивалентных составных терминов американского варианта английского языка особую сложность составляет передача значения неядерного элемента, с помо- щью которого специализируется понятие, обозначаемое основным смысловым термином и имеющее аналог в языке перевода. Терминоэлементы, обеспечивающие выражение категориального признака в структуре ряда безэквивалентных терминов, могут быть калькированы, хотя отсутствие видового понятия в переводящем языке (ПЯ) препятствует идентичности восприятия языковой единицы носителями иностранного языка (ИЯ) и ПЯ.

Таким образом, при анализе приемов и способов перевода, выявленных в исследовании, безэквивалентных составных терминов в сфере американской экономики выявляются следующие закономерности:

- при переводе безэквивалентной терминологии может быть использован описательный перевод с ИЯ на ПЯ;

- при переводе подавляющего большинства безэквивалентных терминов может быть применен прием калькирования;

- подавляющее большинство безэквивалентных терминов может быть переведено посредством калькирования (замена частей речи, лексическая замена).

В итоге изучения процесса функционирования безэквивалентных терминов в английском языке и анализа их перевода на русский язык (на материале американских экономических журналов) можно утверждать, что явление безэквивалентности возникает вследствие отсутствия или недифференцированности того или иного понятия, обозначаемого термином ИЯ, в терминосистеме ПЯ.

\section{ЛИТЕРАТУРА}

1. Борисова Л.И. Особенности перевода общеупотребительной и общенаучной лексики с английского языка на русский. / Л.И. Борисова. — Москва: ВЦП, 2000. $-171 \mathrm{c}$.

2. Головин Б.Н. Роль терминологии в научном и учебном общении. Термин и слово. - Горький: Изд-во ГГУ им. Н.И. Лобачевского, 2000. - С. $14-25$.

3. Довбыш 0.В. Английская финансовая терминология и проблемы ее перевода на русский язык: на материале годовых финансовых отчетов зарубежных компаний: дисс. . . канд. филолог. наук. /0.В. Довбыш. - Москва, 2003. -186с.

4. Капанадзе Л.А. 0 понятияХ «термин» и «теминология». Развитие лексики современного русского языка. / Л.А. Капанадзе. - Москва: Наука, 2005. - 135 с.

5. Латышев Л.К. Курс перевода: Эквивалентность перевода и способы ее достижения / Л.К. Латышев. - Москва: Международные отношения, 2001. - 260 с.

6. Овчаренко В.М. Термины, аналитическое наименование и номинативное определение. Современные проблемы терминологии в науке и технике. / В.М. Овчаренко. - Москва: Наука, 2001. - 215 с.

7. Разинкина Н.М. Развитие языка английской научной литературы. / Н.М. Разинкина. — М: Наука, 2003. - 212 с.

8. Реформатский А.А. Что такое термин и терминология. Вопросы терминологии/ А.А. Реформатский. - М.: Издательство АН, 2000. - 192 с.

9. American Economic Journal: Applied Economics. - URL: https://yandex.ru/search/?text=American\%20Economic\%20Journal\%20\&lr=21641\&clid=2402253632\&win=448 (Дата обращения: 10.03 .2021 ).

10. The American Economic Review. - URL: https://www.aeaweb.org/journals/(Дата обращения: 12.03.2021).

(c) Амбарцумян Екатерина Меружановна (katrin01_89@mail.ru).

Журнал «Современная наука: актуальные проблемы теории и практики» 